\title{
The propensity for entrepreneurship among rural populations. A Central and Eastern European country perspective
}

\author{
Carmen PĂUNESCU \\ Bucharest University of Economic Studies, UNESCO Department for Business Administration, \\ Bucharest, Romania \\ carmen.paunescu@ase.ro \\ Daniela STAICU \\ Bucharest University of Economic Studies, Doctoral School for Business Administration, \\ Bucharest, Romania \\ danielastaicu@gmail.com \\ Oana POP \\ Bucharest University of Economic Studies, Doctoral School for Business Administration, \\ Bucharest, Romania \\ oana.pop.cv@gmail.com
}

\begin{abstract}
The paper aims to assess the propensity for entrepreneurship among rural populations in ten Central and Eastern European (CEE) countries. The entrepreneurship propensity is measured against four dimensions: entrepreneurial potential, desirability of self-employment, feasibility of selfemployment and the comfort with acquiring customers. In addition, we analysed key motivations for self-employment among rural populations in the sample countries, namely: the prospects of second income; self-fulfilment and possibility to realize own dreams and ideals; and return to job market as alternative to unemployment. The objectives of the paper are three-folded: (1) To determine how likely are the rural populations in the CEE countries studied to take on a self-employment activity; (2) To understand the perception of rural populations in the CEE countries about entrepreneurship and selfemployment; and (3) To identify the apparent similarities and differences in the countries studied among the rural populations in terms of their perception about entrepreneurship and motivations for self-employment. The study interprets the data collected in 2016 through the Amway Global Entrepreneurship Report. The research is meant to foster and popularize the rural entrepreneurship career model among rural communities in the sample CEE countries. This is important in order to know what can be done to encourage the business continuation and growth of rural entrepreneurs.
\end{abstract}

Keywords: rural entrepreneurship, propensity for entrepreneurship, motivations for selfemployment, Central and Eastern European countries, AGER.

\section{Introduction}

New trends in economic development and the emergence of knowledge-based economy have resulted in more attention being given to entrepreneurship across the world and all segments of population. Entrepreneurship plays quite an important role in promoting economic growth and social development, contributing not just to employment, social and political stability, but also to a nation's innovativeness and competitive power.

Rural entrepreneurship and community based entrepreneurship are recognized as vital to economic development of local or regional communities and sustainability worldwide. However, the literature is scarce in information on rural entrepreneurs, their 
challenges and motivations: who they are, what type of businesses they have, what drives them for self-employment, what problems they have faced (Salleh \& Sidek, 2011; Azzahra \& Dhewanto, 2015; Fortunato \& Alter, 2016). Rural communities' talents, energy and ideas overall are one of the most under-utilized business resources, often wasted. Therefore, it is imperative to enable and support rural communities fully and constructively participate in the economic activities of their countries or communities.

PICBE $\mid 729$

The current paper aims to discuss how the propensity for entrepreneurship varies among rural populations in ten Central and Eastern European (CEE) countries, namely: Bulgaria, Croatia, The Czech Republic, Estonia, Hungary, Lithuania, Poland, Romania, Slovakia and Slovenia. Propensity for entrepreneurship is measured against four core dimensions: entrepreneurial potential, desirability, feasibility and comfort with recruiting customers. Also, motivations for self-employment among rural populations are analysed in the paper to complement our understanding about entrepreneurship propensity. The paper starts with a brief review of the literature. Then it explains the methodology used to assess the propensity for entrepreneurship among rural populations. Finally, analysis is conducted on selected data and conclusions are drawn based on results.

\section{Literature review \\ Insights into rural entrepreneurship}

The development of community-based entrepreneurship in the rural areas is vital in order to support local services, promote the resilience of rural localities and communities as well as improve the quality of life of the rural residents. Entrepreneurship is a viable alternative to employment for rural areas given that paid work opportunities are quite rare in those communities. Moreover, rural entrepreneurship development and employment generation are fundamental to enhancing local-level progress and transformation.

Achieving gainful employment in rural communities contributes immensely to the increase of quality of life and realization of the potential of people living in remote communities (Kolawole \& Ajila, 2015). National governments invest in initiatives aimed at encouraging community-based entrepreneurship on the assumption that it contributes to competitiveness and employment. However, this is not always easy to generate. Kasabov (2016) identified three personal traits that explain rural entrepreneurship difficulties and failure in Thailand, namely risk aversion, passivity and over-reliance on the public sector. These characteristics complement entrepreneurship resource weaknesses in rural communities. Thus, entrepreneurship in the rural context become extremely important because it assists to complement scarce resources and create new opportunities for rural development base by facilitating networking and partnering between rural actors with other actors (Hukampal \& Bhowmick, 2016).The results of a study done by Goraj and Gwiazdzinska-Goraj (2016) revealed that the higher the demographic potential of rural communes was, the more favorable indicators of growth of entrepreneurship appeared. As such, the demographic potential of workforce and its predisposition for self-employment proved to have a considerable impact on the development of the rural areas of NorthEastern Poland.

Other researchers (Alemu \& Adesina, 2017) found that education, rural cooperation, access to transport, communication, and access to credit are among the main drivers of households' engagement in enterprises that are non-farm in Africa. Moreover, Muhammad et al. (2017) argued that religious, socio-economic context and structural forces play a 
significant role in attaining a low level of entrepreneurship in rural areas of Pakistan, agrobased regions, as these are not favorable to sustaining the social capital development.

Nagler \& Naude (2017) discovered that enterprises operated by rural households in sub-Saharan Africa are predominantly found in domains such as sales and trade, and include less activities that require higher starting costs, such as construction or transport services, or even professional services. They also found that rural and, particularly, femaleheaded enterprises seem to achieve lower levels of labor productivity and consequently modest financial results compared to urban and male-owned enterprises. Moreover, the most prevalent reason for exiting the market of rural enterprises it due to a poor profitability or lack of financial resources.

Community sustainability has been found to have a paramount contribution to economic growth, by enhancing the revenues of the national government, reducing the unemployment rate and enriching the human capital skills. For example, in declining rural areas in Netherlands, the side-activities performed by female farmers were seen as having the potential to keep communities from migrating to other territories by contributing to household income and increasing the quality of life (Markantoni and Van Hoven, 2012). As engagement and payback to their local communities are fundamental to their professional, strategic and operational goals, female rural entrepreneurs develop activities that display the significant potential of becoming an important part of the community development policies and practices (Wang and Morrell, 2015).

Potential for development of community-based entrepreneurship in rural areas depends on the existence of favorable micro-social and cultural conditions at the local level, which may influence individuals' entrepreneurial predisposition. This in turn will lead towards a better understanding of the entrepreneurial activities (Păunescu et al., 2016), with all their success, risk and failure.

\section{Methodology}

The current paper aims to explore the propensity for entrepreneurship among rural populations in ten Central and Eastern European (CEE) countries. The objectives of the paper are three-folded: (1) To determine how likely are the rural populations in the CEE countries studied to take on a self-employment activity; (2) To understand the perception of rural populations in the CEE countries about entrepreneurship and self-employment; and (3) To identify the apparent similarities and differences in the countries studied among the rural populations in terms of their perception about entrepreneurship and motivations for self-employment.

The propensity for entrepreneurship is measured against four key dimensions: entrepreneurial potential, desirability, feasibility and comfort with acquiring customers. Entrepreneurial potential assesses the perceived interest in starting a business and being self-employed regardless of the attitude displayed about self-employment, either positive or negative. Desirability measures perception about starting a venture as a desirable career opportunity. Feasibility measures the perceived preparedness for starting a business and the perception about possessing the necessary skills, capabilities and resources for running the business. Comfort with identifying and acquiring customers assesses the perceived preparedness to search for, recruit and retain own customers as a self-employed person.

To complement our understanding about the propensity for entrepreneurship among rural populations in the ten CEE countries, we also measured their motivations for 
self-employment, namely: the prospects of second income as a result of a better paid and more rewarding job; self-fulfilment in what regards actualizing one's own dreams and ideals; and return to job market as alternative to unemployment.

Data analysed in the paper are extracted from the Amway Global Entrepreneurship Report (AGER) 2016 and regard ten CEE countries: Bulgaria, Croatia, The Czech Republic, Estonia, Hungary, Lithuania, Poland, Romania, Slovakia and Slovenia. The AGER survey takes the public pulse of the state of entrepreneurship around the world. In 2016 it reached its seventh edition worldwide and its fourth edition in Romania. The research conducted in 2016 included 45 countries and spanned over 50,000 men and women aged 14-99 worldwide. The survey was carry-out through face-to-face or telephone interviews, by using a fully structured questionnaire, with questions asked in a given order and wording. The procedures used to select participants from the whole universe of each market population ensure a representative sample in each country.

In the paper we make the following assumptions: (1) The propensity for entrepreneurship is relatively low among rural populations in our sample countries; (2) Motivations for self-employment vary significantly among the rural populations in the CEE countries studied; and (3) There are countries in our sample which share similar characteristics in terms of perception about entrepreneurship and self-employment motivations and there are also differences which stand out as really significant.

\section{Results and discussions}

The sample populations in the CEE countries investigated include rural populations or small-sized communities in those countries. The sample size extends from 253 respondents in Estonia and 254 in Hungary up to 469 respondents in Slovakia and 453 in Romania (Table 1). The structure of sample populations by gender indicates a slight larger female population among respondents in most of the countries, except Romania where there is an even balance between genders (Figure 1).

Table 1. Sample rural populations

\begin{tabular}{|c|c|c|c|}
\hline Country & $\begin{array}{c}\text { Total } \\
\text { respondents }\end{array}$ & Females & Males \\
\hline Bulgaria & 301 & 154 & 147 \\
Croatia & 388 & 208 & 180 \\
The Czech Republic & 407 & 207 & 200 \\
Estonia & 253 & 134 & 119 \\
Hungary & 254 & 133 & 121 \\
Lithuania & 334 & 177 & 157 \\
Poland & 390 & 227 & 163 \\
Romania & 453 & 228 & 225 \\
Slovakia & 469 & 256 & 213 \\
Slovenia & 230 & 119 & 111 \\
\hline
\end{tabular}

Source: AGER 2016 data. 


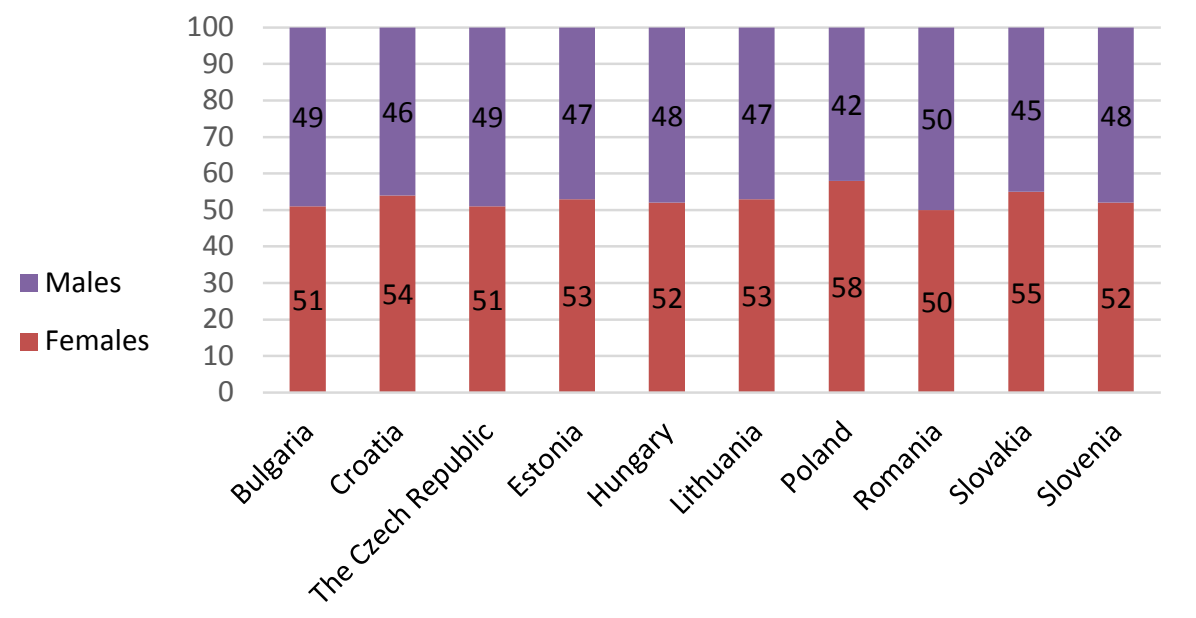

PICBE | 732

Figure 1. Sample rural populations by gender (\%)

Source: Authors' own research. Processed based on AGER 2016 data.

To determine the propensity for entrepreneurship among the rural populations in the ten CEE countries investigated we analysed independently the four key dimensions of the entrepreneurial activity, namely: entrepreneurial potential, desirability, feasibility and comfort with acquiring customers. Then, we aggregated the results using the arithmetic mean and the resultant weight was assimilated to predisposition for entrepreneurship for the populations studied.

Consequently, in what regards the entrepreneurial potential, there is a relatively medium to high perceived interest in starting a venture among rural populations in countries like Lithuania (61\% - males, 42\% - females), Estonia (52\% - males, $46 \%$ females), Slovenia (54\% - males, 35\% - females), even Poland (50\% - males, 38\% - females) and Czech Republic (51\% - males, 29\% - females). Entrepreneurial potential overall seems to be higher for men than for women in all of the countries studied. A quite low interest in self-employment is found in Romania (23\% - males, $13 \%$ - females) and Bulgaria (16\% males, 6\% - females), the lowest in our sample (Figure 2).

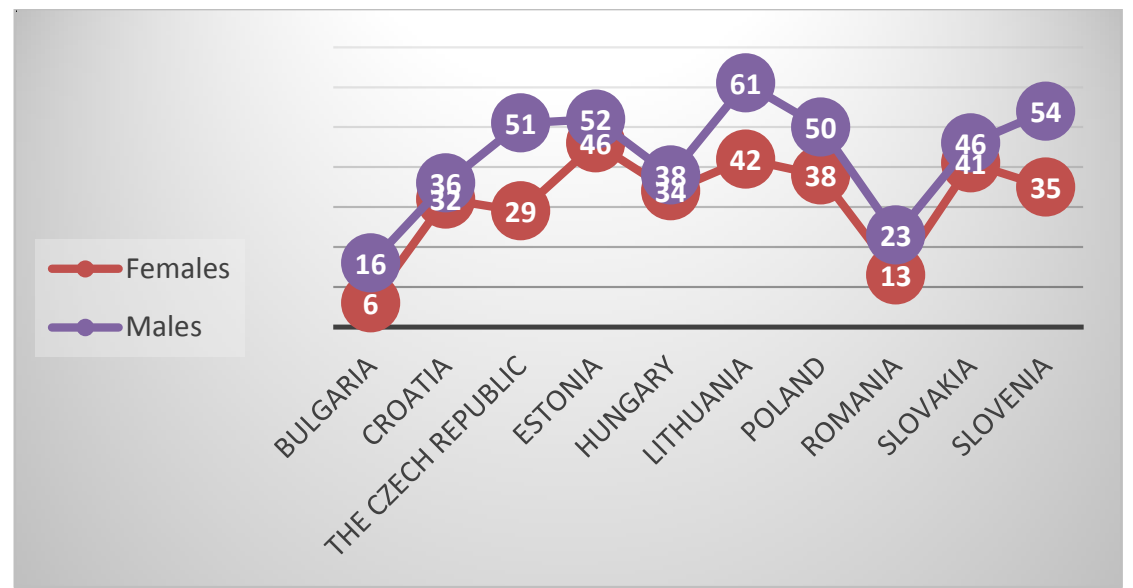

Figure 2. Entrepreneurial potential among rural populations (\%)

Source: Authors' own research. Processed based on AGER 2016 data. 
To what concerns the desirability of self-employment, our research reveals high approvals for entrepreneurship as a desirable career opportunity in countries like Lithuania (78\% - males, $81 \%$ - females), Slovenia (72\% - males, $71 \%$ - females), Slovakia (63\% - males, 54\% - females), even Czech Republic (56\% - males, 47\% - females) and Estonia (50\% - males, $48 \%$ - females); low approvals are found in Bulgaria (16\% - males, $14 \%$ - females) and Poland (25\% - males, 19\% - females) (maybe because of the political instability) (Figure 3). Desirability of self-employment seems to be higher for women in Poland, and below men's ambition in all the other countries from our sample. In Hungary gender does not make any difference from this perspective.

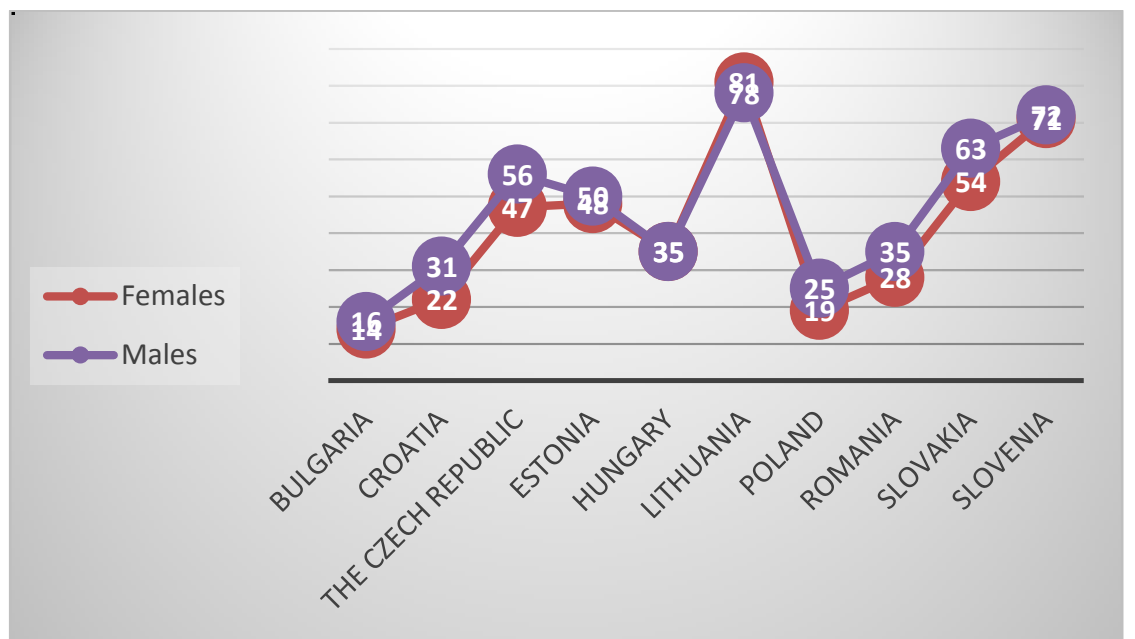

Figure 3. Desirability of self-employment among rural populations (\%)

Source: Authors' own research. Processed based on AGER 2016 data.

Looking at the feasibility of self-employment our research reveals medium to high approvals in Slovenia (59\% - males, 48\% - females), Lithuania (54\% - males, 32\% females), Croatia (43\% - males, 38\% - females) and Estonia (47\% - males, 31\% - females), whilst in Bulgaria (12\% - males, 6\% - females), Hungary (19\% - males, 14\% - females) or Romania (20\% - males, $15 \%$ - females) rural populations seem like they are not prepared yet for starting a business (Figure 4). Overall men seem to be more prepared than women to start a business in all of the sample countries. Differences are larger in Lithuania, The Czech Republic and Estonia, and smaller in Croatia, Hungary and Romania.

In what regards the perceived comfort with acquiring customers this is quite high in Lithuania (80\% - males, 76\% - females), Slovenia (73\% - males, 55\% - females), Croatia (62\% - males, 62\% - females), Poland (64\% - males, 56\% - females) and even Estonia (62\% - males, $46 \%$ - females) and comparatively very low in Bulgaria (18\% - males, 17\% females). It also is relatively low in Hungary (38\% - males, $26 \%$ - females) and Romania (36\% - males, 29\% - females) (Figure 5). Men seem to be more confident in their selling and negotiation skills than women in most of the countries from our sample. Also, there is no difference by gender from this perspective in Croatia, even Bulgaria. 


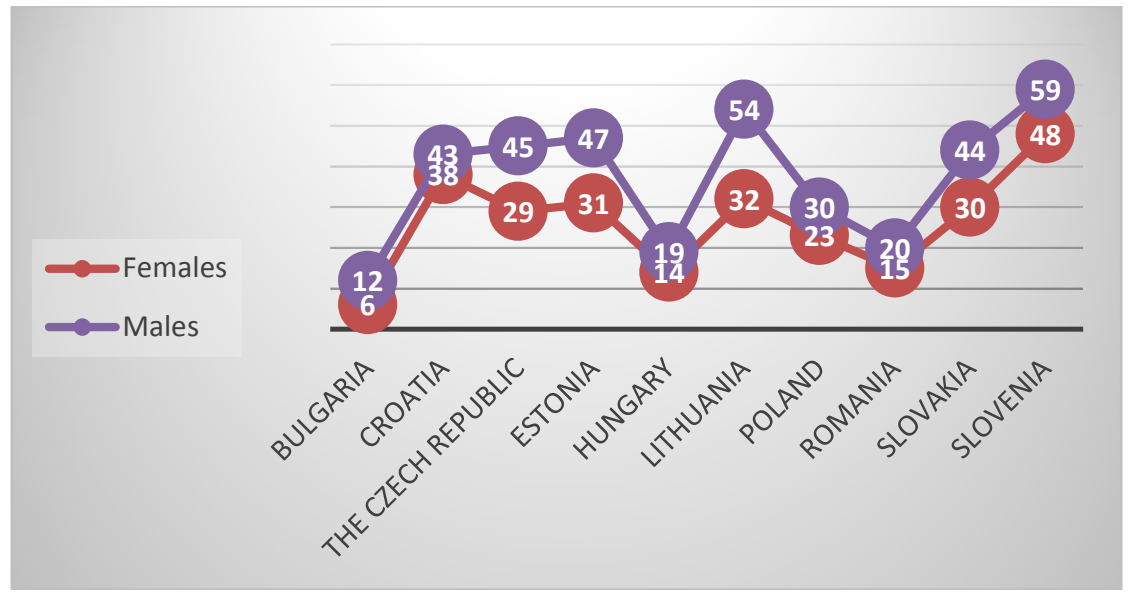

PICBE | 734

Figure 4. Feasibility of self-employment among rural populations (\%)

Source: Authors' own research. Processed based on AGER 2016 data.

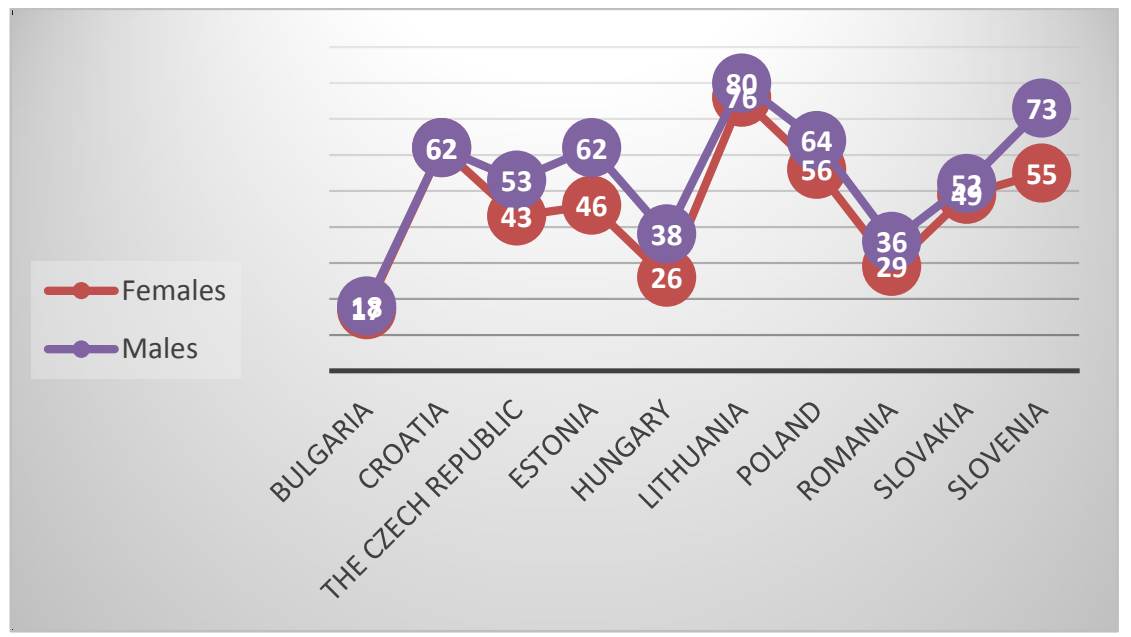

Figure 5. Comfort with acquiring customers among rural populations (\%)

Source: Authors' own research. Processed based on AGER 2016 data.

Our findings indicate that the propensity for entrepreneurship among rural populations in the sample countries, on average, is medium with a score of $41 \%$ (37\% females, $45 \%$ - males), bellow the middle point but still a promising result (Table 2 ). The highest approvals for self-employment were reached in Lithuania - 63\% (58\% - females, 68\% - males) and Slovenia - 59\% (52\% - females, 65\% - males). These are followed closely by Estonia - 48\% (43\% - females, 53\% - males) and Slovakia - 48\% (44\% - females, 51\% males). The lowest approvals are found in Bulgaria - 14\% (11\% - females, 16\% - males), Romania - 25\% (21\% - females, 29\% - males) and Hungary - 30\% (27\% - females, 33\% males). The scores are lower in all countries for women relative to men.

When it comes to female rural populations' motivations for entrepreneurship, second income prospects is the first motivator for women in Lithuania (53\%), Croatia (45\%), Romania (39\%), Hungary (31\%) and Bulgaria (19\%) (Figure 6). Self-fulfilment and possibility to realize own dreams is a prevalent motivation for women in Slovenia (60\%), Estonia (49\%), Poland (37\%) and Czech Republic (34\%), whilst return to job market is a apparent motivation for women in Slovenia (39\%). 
Table 2. Propensity for entrepreneurship among rural populations (\%)

\begin{tabular}{|c|c|c|c|c|c|c|c|c|c|c|}
\hline \multirow{2}{*}{ Country } & \multicolumn{5}{|c|}{ Females } & \multicolumn{4}{|c|}{ Males } & \multirow{2}{*}{$\begin{array}{l}\text { Country } \\
\text { average }\end{array}$} \\
\hline & Potential & Desirab & Feasib & omfort & Mean & Potential Desirab & Feasib & Comfort & Mean & \\
\hline Bulgaria & 6 & 14 & 6 & 17 & 11 & 16 & 12 & 18 & 16 & 14 \\
\hline Croatia & 32 & 22 & 38 & 62 & 39 & 31 & 43 & 62 & 43 & 41 \\
\hline $\begin{array}{l}\text { The Czech } \\
\text { Republic }\end{array}$ & 29 & 47 & 29 & 43 & 37 & 56 & 45 & 53 & 51 & 44 \\
\hline Estonia & 46 & 48 & 31 & 46 & 43 & 52 & 47 & 62 & 53 & 48 \\
\hline Hungary & 34 & 35 & 14 & 26 & 27 & 38 & 19 & 38 & 33 & 30 \\
\hline Lithuania & 42 & 81 & 32 & 76 & 58 & 61 & 54 & 80 & 68 & 63 \\
\hline Poland & 38 & 19 & 23 & 56 & 34 & 50 & 30 & 64 & 42 & 38 \\
\hline Romania & 13 & 28 & 15 & 29 & 21 & 35 & 20 & 36 & 29 & 25 \\
\hline Slovakia & 41 & 54 & 30 & 49 & 44 & 46 & 44 & 52 & 51 & 48 \\
\hline Slovenia & 35 & 71 & 48 & 55 & 52 & 54 & 59 & 73 & 65 & 59 \\
\hline CEE & & Females & iverag & & 37 & Males av & verage & & 45 & 41 \\
\hline
\end{tabular}

PICBE | 735

Source: Authors' own research. Processed based on AGER 2016 data.

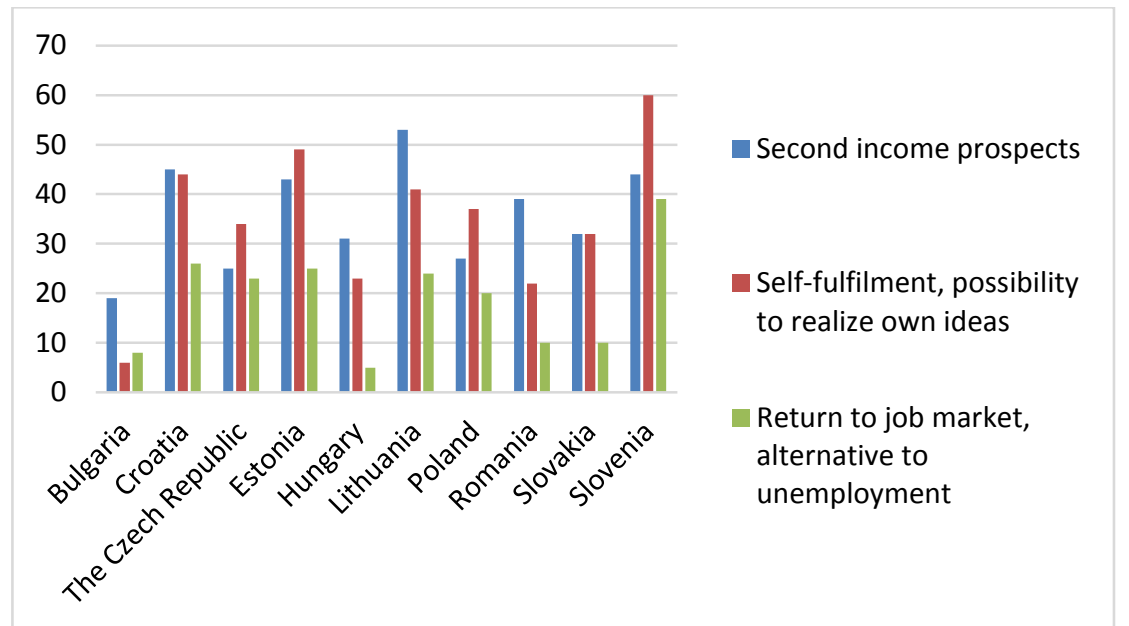

Figure 6. Motivations for self-employment among female rural populations (\%)

Source: Authors' own research. Processed based on AGER 2016 data.

For male rural populations, second income prospects is the first motivator for men in countries like Romania (46\%), Croatia (43\%), Lithuania (39\%), Slovakia (36\%), Hungary (26\%) and Bulgaria (23\%) (Figure 7). Self-fulfilment is a prevalent motivation for male rural populations in Estonia (57\%), Slovenia (44\%), Czech Republic (40\%) and Poland (36\%), whilst return to job market comes at the end. 


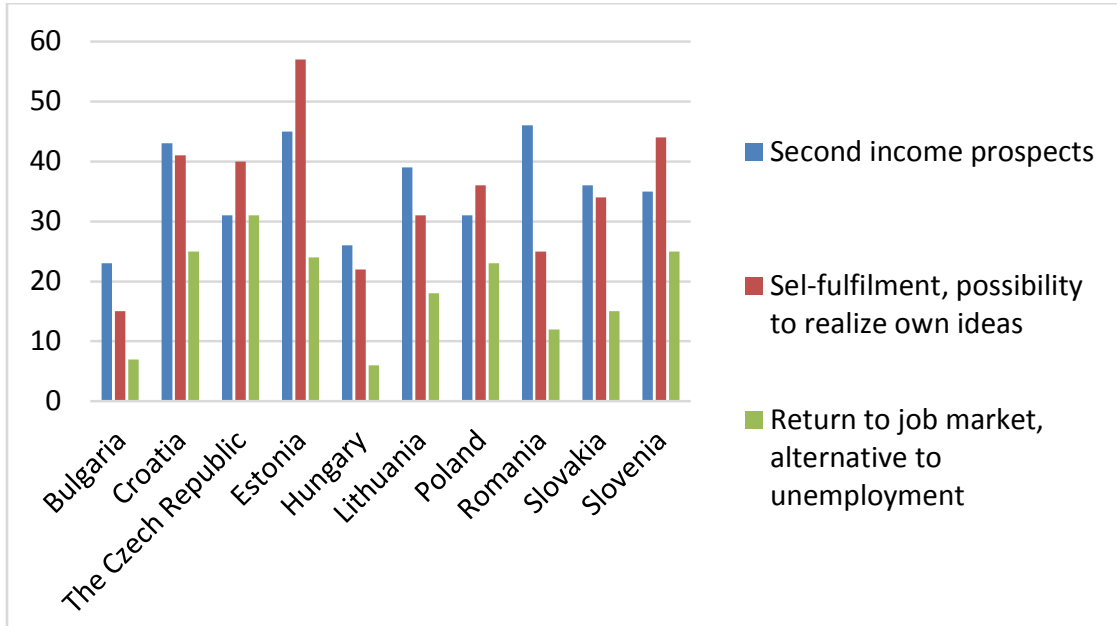

PICBE | 736

Figure 7. Motivations for self-employment among male rural populations (\%)

Source: Authors' own research. Processed based on AGER 2016 data.

Therefore, rural populations in our sample countries are motivated differently to start a self-employed career. As such, second income prospects represent a prevalent motivation for self-employment among rural populations in Lithuania (46\%), Croatia (44\%), Estonia (44\%), Romania (43\%) and Slovenia (40\%). Self-fulfilment is an apparent motivator in Estonia (53\%), Slovenia (52\%) and Croatia (43\%), whilst return to job market comes at the end with 32\% approvals in Slovenia, 27\% - The Czech Republic, 26\% - Croatia and $25 \%$ - Estonia.

Our research findings also reveal that self-fulfilment and possibility to realize own ideas is not a motivation to start a business in Bulgaria, and influences to some extend the decision to start a business in Hungary and Romania (for both males and females). Similarly, return to job market as alternative to unemployment is not a motivation for selfemployment in countries like Hungary, Bulgaria, even Romania and Slovakia. On average, second income prospects is a main motivator for self-employment for $36 \%$ of the rural populations in the sample of CEE countries, followed by self-fulfilment and possibility to realize own ideas (35\%) and return to job market (19\%) (Table 3).

Table 3. Motivations for entrepreneurship among rural populations (\%)

\begin{tabular}{|c|c|c|c|c|c|c|c|c|c|}
\hline \multirow[t]{2}{*}{ Country } & \multicolumn{3}{|c|}{ Second income prospects } & \multicolumn{3}{|c|}{$\begin{array}{c}\text { Self-fulfilment, possibility to } \\
\text { realize own ideas }\end{array}$} & \multicolumn{3}{|c|}{$\begin{array}{l}\text { Return to job market, } \\
\text { alternative to } \\
\text { unemployment }\end{array}$} \\
\hline & Females & Males & Average & Females & Males & Average & Females & Males & Average \\
\hline Bulgaria & 19 & 23 & 21 & 6 & 15 & 11 & 8 & 7 & 8 \\
\hline Croatia & 45 & 43 & 44 & 44 & 41 & 43 & 26 & 25 & 26 \\
\hline $\begin{array}{l}\text { The Czech } \\
\text { Republic }\end{array}$ & 25 & 31 & 28 & 34 & 40 & 37 & 23 & 31 & 27 \\
\hline Estonia & 43 & 45 & 44 & 49 & 57 & 53 & 25 & 24 & 25 \\
\hline Hungary & 31 & 26 & 29 & 23 & 22 & 23 & 5 & 6 & 6 \\
\hline Lithuania & 53 & 39 & 46 & 41 & 31 & 36 & 24 & 18 & 21 \\
\hline Poland & 27 & 31 & 29 & 37 & 36 & 37 & 20 & 23 & 22 \\
\hline Romania & 39 & 46 & 43 & 22 & 25 & 24 & 10 & 12 & 11 \\
\hline
\end{tabular}




\begin{tabular}{|c|cc|c|cc|c|cc|c|}
\hline $\begin{array}{c}\text { Slovakia } \\
\text { Slovenia }\end{array}$ & 32 & 36 & $\mathbf{3 4}$ & 32 & 34 & $\mathbf{3 3}$ & 10 & 15 & $\mathbf{1 3}$ \\
\hline CEE & $\begin{array}{c}\text { Average } \\
\text { overall }\end{array}$ & $\mathbf{3 6}$ & $\begin{array}{c}\text { Average } \\
\text { overall }\end{array}$ & $\mathbf{3 5}$ & $\begin{array}{c}\text { Average } \\
\text { overall }\end{array}$ & $\mathbf{1 9}$ \\
\hline
\end{tabular}

Source: Authors' own research. Processed based on AGER 2016 data.

\section{Conclusion}

The paper presented the key results on rural entrepreneurship from the Amway Global Survey 2016 in ten Central and Eastern European countries. It offered insights in how the rural populations saw the current situation of entrepreneurship in their communities.

The research results indicate that Lithuania is leading the table in all dimensions (entrepreneurial potential, desirability of self-employment, feasibility of self-employment and comfort with recruiting customers), Slovenia is following closely behind and Estonia is coming on next. Bulgaria is left behind in all dimensions while Romania, Hungary and Poland are sharing almost similar challenges. Also, it seems like Hungary, Bulgaria, Romania and Slovakia do not show strong motivation to self-employment and challenge for change. We also found that there is a decent level of comfort with searching and acquiring customers in most of the CEE countries studied.

Our research findings revealed that the propensity for entrepreneurship among rural populations in the sample CEE countries, on average, was medium (41\%), higher for males (45\%) and lower for women (37\%). The highest approvals for self-employment were reached in Lithuania (63\%), Slovenia (59\%), Estonia (48\%) and Slovakia (48\%), whilst the lowest scores were found in Bulgaria (14\%), Romania (25\%) and Hungary (30\%). The scores are lower in all countries for women relative to men.

Moreover, the research results indicate that rural populations in our sample countries were motivated differently to start a self-employed career: second income prospects represent a prevalent motivation in Lithuania, Croatia, Estonia, Romania and Slovenia; self-fulfilment is an apparent motivator in Estonia, Slovenia and Croatia, whilst return to job market is a main motivation in Slovenia, The Czech Republic, Croatia and Estonia.

Our research findings also revealed that self-fulfilment and possibility to realize own ideas is not a motivation to start a business in Bulgaria, and influences to some extend the decision to start a business in Hungary and Romania. Finally, on average, second income prospects is a main motivator for self-employment for $36 \%$ of the rural populations in the sample of CEE countries, followed by self-fulfilment and possibility to realize own ideas (35\%) and return to job market (19\%).

To conclude all our research assumptions proved to be confirmed through analysis. The propensity for entrepreneurship among rural populations in our sample countries remained relatively low and the motivations for self-employment differ even if there are countries which share similar characteristics regarding entrepreneurship perception. There are also differences of perception between countries which stand out as really significant. Thus, there is more to be done in the CEE countries investigated in order to enhance acceptability of self-employment, to cultivate the desire to start a business and to increase confidence in people's own abilities and capabilities. Rural populations have probably started recognizing the necessity of entrepreneurship. However, it may need a few more years for them to start witnessing the real value of entrepreneurship locally. 


\section{References}

Alemu, A.E., \& Adesina, J.O. (2017). In search of rural entrepreneurship: Non-farm household enterprises (NFEs) as instruments of rural transformation in Ethiopia. African Development Review, 29(2), 259-271.

Azzahra, S., \& Dhewanto, W. (2015). Entrepreneurship training for community in rural area: Motivation and knowledge of entrepreneurship. Advanced Science Letters, 21(6), SI, 1858-1862.

Fortunato, M.W.P., \& Alter, T.R. (2016). Culture and entrepreneurial opportunity in highand low-entrepreneurship rural communities. Challenging the discovery/creation divide. Journal of Enterprising Communities-People and Places of Global Economy, $10(4), 447-476$.

Goraj, S., \& Gwiazdzinska-Goraj, M. (2016). Development of entrepreneurship in rural areas of North-Eastern Poland. Economic Science for Rural Development: Rural Development and Entrepreneurship Bioeconomy Home Economics, 41, 61-68.

Hukampal, S.S., \& Bhowmick, B. (2016). Innovation network for entrepreneurship development in rural Indian context: Exploratory factor analysis. International Journal of Innovation and Technology, 13(4), no. 1650016.

Kasabov, E. (2016). When an initiative promises more than it delivers: a multi-actor perspective of rural entrepreneurship difficulties and failure in Thailand. Entrepreneurship and Regional Development, 28(9-10), 681-703.

Kolawole, O.D., \& Ajila, K. (2015). Driving local community transformation through participatory rural entrepreneurship development. World Journal of Entrepreneurship Management and Sustainable Development, 11(2), 131-139.

Markantoni, M., \& van Hoven, B. (2012). Bringing the 'invisible' side activities to light. A case study of rural female entrepreneurs in the Veenkoloniën. Journal of Rural Studies, 28(4), 507-516.

Muhammad, N., McElwee, G., \& Dana, L.P. (2017). Barriers to the development and progress of entrepreneurship in rural Pakistan. International Journal of Entrepreneurial Behaviour \& Research, 23(2), 279-295.

Nagler, P., \& Naude, W. (2017). Non-farm entrepreneurship in rural sub-Saharan Africa: New empirical evidence. Food Policy, 67, 175-191.

Păunescu, C., Pascu, A.I., \& Pop, O. (2016). Social enterprise: How does this way of doing business differ from other forms of enterprise? Quality - Access to Success, 17(153), 108-110.

Salleh, M., \& Sidek, N. (2011). Rural entrepreneurship: a challenges and opportunities of rural micro enterprise (RME) in Malaysia. Interdisciplinary Journal of Contemporary Research in Business, 2(11), 573-585.

Wang, Q., \& Morrell, E. (2015). Gender and entrepreneurship revisited from a community perspective: experiences in a new immigrant gateway and beyond. Environment and Planning A, 47(12), 2645-2662. 